\title{
Enterprise Information Systems as a Service: Re-engineering Enterprise Software as Product-Service System
}

\author{
J.C. ("Hans") Wortmann ${ }^{1}$, Hans Don ${ }^{2}$, Jan Hasselman ${ }^{2}$, and Alex Wilbrink ${ }^{2}$ \\ ${ }^{1}$ Groningen University, The Netherlands \\ ${ }^{2}$ Vanenburg Software, The Netherlands
}

\begin{abstract}
This paper draws an analogy between developments in enterprise software and in capital goods manufacturing industry. Many branches of manufacturing industry, especially automotive industry, have grown in maturity by moving from craftsmanship to mass production. These industries subsequently move from mass production towards mass customization, introducing lean practices. Finally, full maturity is reached by increased servitization resulting in product-service systems (PSS).

This paper analyzes the developments of enterprise information systems in the same terms. The paper shows that the enterprise software follows a similar pattern as capital goods manufacturing industries, with a few interesting differences.

However, lean delivery of enterprise applications is still at the threshold of being practised. Lean delivery requires single versions of applications and delivery in multi-tenant mode. Combining lean delivery with large variety requires automated configuration of application systems components. This is enabled by software-as-a-service from the cloud. Enterprise software "from the cloud" is comparable to servitization in other branches of industry. It goes together with re-engineering enterprise software according to the SaaS paradigm.
\end{abstract}

Keywords: Enterprise information systems, SaaS, ERP, Cloud computing, servitization.

\section{$1 \quad$ Introduction}

Innovation in manufacturing companies has always gone hand-in-hand with investments in plant equipment and capital goods. However, over the last decades a substantial part of the investments has been spent in enterprise information systems (EIS), such ERP, CRM and SCM. This paper studies the question, if production and distribution EIS is comparable to the production and distribution of capital goods and other physical products.

There is a striking analogy between the developments in many physical supply chains and the developments in the supply of enterprise software. In particular, the 
industry trends towards mass production, increasing variety, multi tier component supply, lean production and servitization can all be recognized in enterprise software supply networks. Cloud computing allows lean supply to be combined with servitization. However, the combination of large variety, lean supply, and servitization is not yet attained in enterprise software. Such a combination will require configurators of standard software components.

This paper provides a short overview of major trends in supply of physical goods in section 2. The analogy with enterprise software is discussed in section 3. Section 4 concludes the paper.

\section{Manufacturing Industry Developments}

\subsection{From Craft Production to Mass Production}

From the beginning of the industrial revolution till the start of the 20th century most production was "craft production" (or one-of-a-kind production). Craft production executes the process of manufacturing by hand with or with the aid of general tools, but not dedicated tools or machinery. A side effect of the craft manufacturing process is that the final product is unique. The product volume for each model was low, while the quality of the product could vary from low to extremely high quality.

\subsection{From Mass Production to Mass Customization (Lean)}

Lean manufacturing aims to bring back or exceed the quality of craft production and remedy the inefficiency of mass production through the elimination of waste. In order to align the variation of demand towards the supply 'mass customization' principles were applied.

Most manufacturers realized though that craft production practices, as well as mass production and lean techniques were still needed to fulfil customer demand. Each of these practices had their own characteristics and logistical principles. Key distinction was the decoupling between demand and supply: the so called 'customer order decoupling point - CODP' (see e.g. Hoekstra and Romme [1992], and Ollhager [2010]).

In order to manage the variability of products, a new product modelling approach was introduced, allowing to represent product platforms or product families (see e.g. Forze and Salvador, 2002, and Wortmann and Alblas [2009]). Generic Bills of Material, generic process sheets (routings), generic pricelists were containing of all optional engineered products. Based on customer preferences the final product variants were configured: created, assembled using existing subassemblies or new produced components (see Figure 1).

As illustrated in the left part of figure 1, the Bill-of-Material structure for a platform takes the form of a diabolo (see Erens [1996]). 


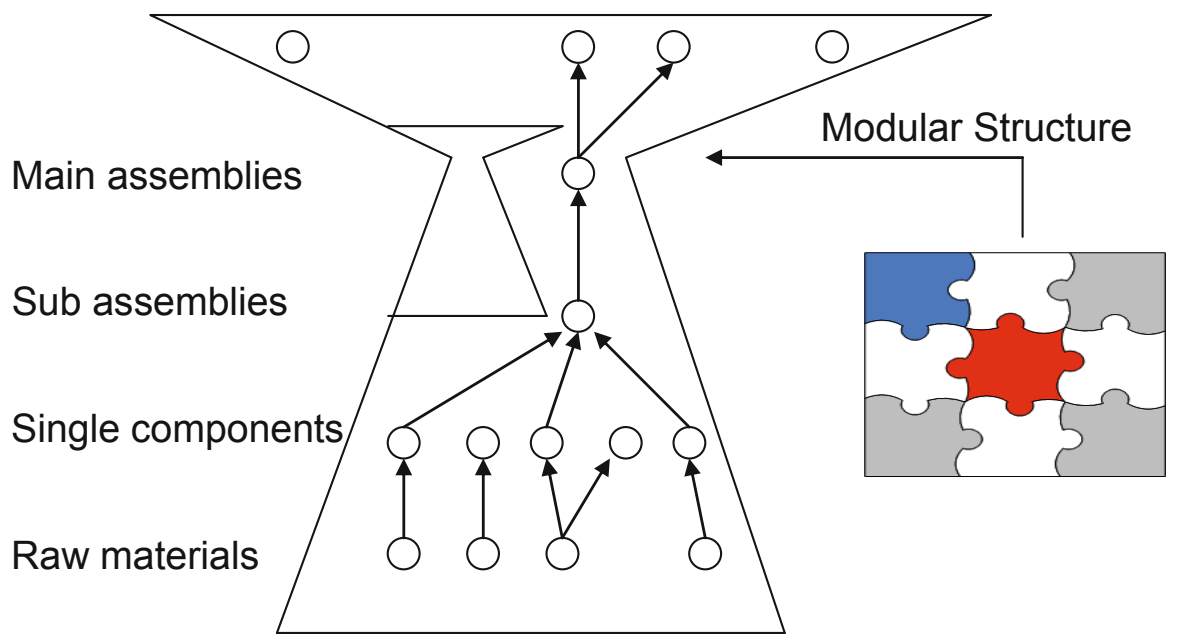

Fig. 1. Product families and platforms

Finally, is should be noticed that the main components of a product family may again be a product family. For example, an engine or gearbox in a vehicle may be a generic product, just like a vehicle. This is illustrated in figure 1 (left) by the small diabolo inside the large diabolo. See Hegge [1992] and Alblas et al.[2010] for elaboration of the generic Bill-of-Material.

In should be noted that there are many configuration solutions which have more domain-specific knowledge than generic bills of material. For example in construction industry, a CAD system for piping solutions can be seen as a configurator, because it allows to create a huge variety of solutions from a limited number of standardized elements (such a pipes with varying lengths and diameters

\subsection{From Mass Customization to Multi-tier Components}

In order to fulfil the increasing market demand, manufacturers moved to preengineered products and services. Subassemblies and modules were standardized. This standardization made the production repeatable at lower costs, due to economies of scale. Tailoring was originally limited to final assembly processes and flexibility was limited to the options provided by the engineers of manufacturers. This results in short lead times: lead times were reduced since subassemblies were made on stock. Interfaces between the standard components were predefined and also standardized.

However, for many sub-assemblies the same principles apply, viz. that their markets enforce the CODP upstream. Accordingly, a world market appears for many products, with an increasing number of tiers and highly specialised manufacturers of materials, components, and subassemblies. The more mature the branch, the more the CODP moves upward. Accordingly, more sophisticated supply chain co-ordination is needed. 
Moreover, the number of tiers in the supply network tends to increase, while the number of different suppliers per product tends to decrease. In other words, the manufacturing Bill of Material gets more levels and less components per level. This is also reflected in the Generic Bill of Material.

\subsection{From Manufacturing towards Outsourcing and Servitization}

In order to survive for manufacturing companies in developed economies, OEM manufacturing firms cannot comprise all value-adding manufacturing activities and at the same time they cannot restrict their activities to manufacturing.

On the one hand, the supply of components had to be outsourced to specialized firms who could apply economies of scale. Outsourcing of non-core activities up or down the supply chain created dynamic business networks to provide value in the most efficient way. Many of the components can be made at lower cost at outside the OEM.

On the other hand, OEM firms have to move beyond manufacturing and offer services and solutions, delivered through their products. Recent technological developments - especially in data capture and information processing - are enabling manufacturing firms to develop new business models, exploiting the potential of their products over the life cycles.

Servitization of capital goods was introduced a few decades ago. An example is the photo copying industry, who started to lease (rather than sell) their machines. In automotive industry, the fleet owners pushed servitization of passenger cars by requesting lease contracts with full service. Life cycle costing became popular in many markets where customers invest in capital goods, and vendors accordingly started to offer service contracts.

In academic literature, the trend towards servitization of physical products is also reflected. Of ten the term product service system (PSS) is used (see e.g. Mont [2002], Tukker and Tischner [2006], Aurich et al. [2009], and Shimomura and Hara [2010]). Key elements are:

- a life cycle costing orientation with suppliers and customers

- focus on service level agreements

- ownership of the physical assets stays with the supplier (often an OEM)

- a network of service suppliers has to be organized for delivery.

\section{Software Industry Developments}

\subsection{From Bespoke Software Engineering to Standard Software}

Several decades ago, in the 1970s and 1980s, application software was largely bespoke, and bespoke software engineering can be characterized as craftsmanship.

Over the years, complete standard enterprise solutions (Enterprise Resource Planning) were built, implemented and deployed. The shift from bespoke enterprise information systems to standard software which took place in the 1990-ties is 
completely in line with the move from craftsmanship to mass production in other branches of industry (see Figure 2 - derived from Womack et al. [1991]).

The client/server based ERP solution was also adopted by the midmarket. The implementation costs were lower and competitive pressure -and therefore the need for automation- also increased for midmarket companies. This is again completely in line with the developments in other markets where the introduction of standard products leads to lower prices and therefore wide-spread adoption in lower market segments.

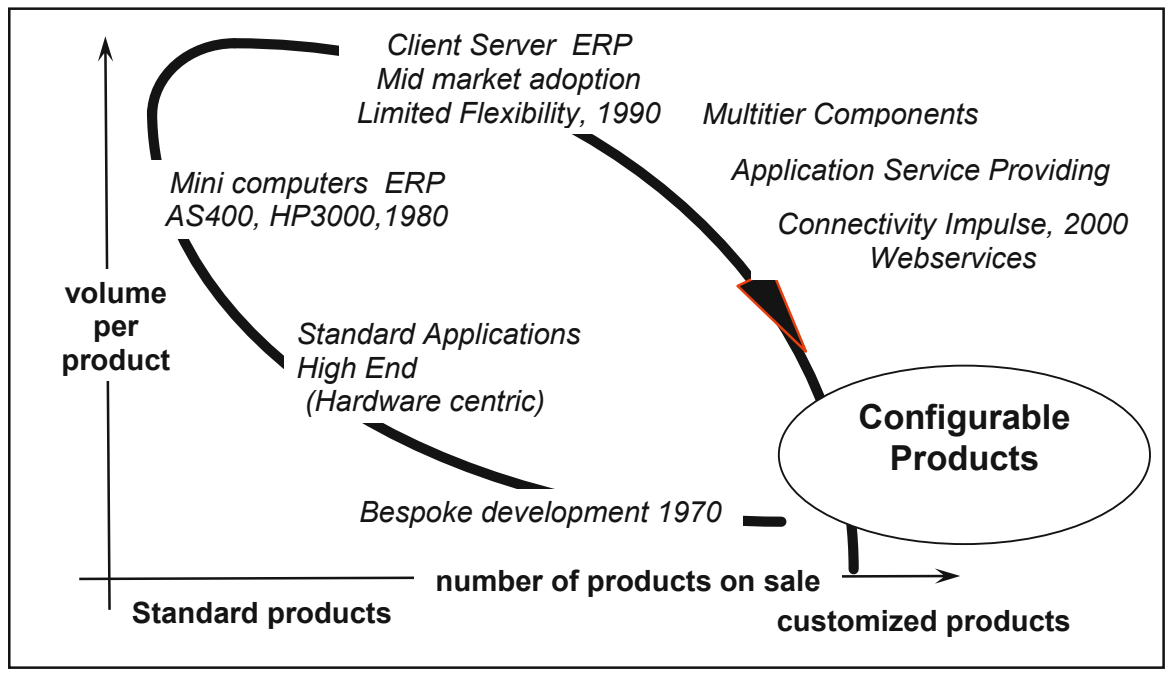

Fig. 2. Development of enterprise applications market

\subsection{From Standard Packages to Multi-tier Software Components}

Vendors of enterprise applications have always adopted mature standard software components, e.g. the database management system. However, other components, such as the license manager, the UI handler, the development toolkits (based on fourth generation languages), and the runtime environment were all developed and maintained by the ERP vendor.

The need for lower prices and more flexibility makes 'bespoke vendor specific development' replaced by solutions assembled from standard components. Large standard software component suppliers such as MicroSoft, Oracle and Google enter the market with software components and tools which are used by vendors of enterprise applications. This development is completely mirroring the development in physical goods manufacturing. 


\subsection{Application Service Providing (ASP) by Hosting: A First Step to Servitization}

The idea of hosting is not new. Application Service Providing (ASP) for long represented the idea of servitization of standard software products. It consists of the following elements:

- The ASP offers the hardware/communication infrastructure to the customer as a service. Therefore, customers do not own this infrastructure and have no operational responsibility. Later this has become known as infrastructure-asa-service (IaaS)

- The ASP offers the systems software, server management, firewalls, database management system and other support software to the customer as a service. Again, the customer does not "own" this software: platform-as-aservice (PaaS)

- The ASP offers the application suite to the customer as a service. Therefore, the customer does not "own" the application but relies on the application service provider to make the application available: this offering is called software-as-a-service (SaaS).

- Payment by the customer to the ASP occurs on a periodic basis, based on actual use by the customer of the services provided by the ASP.

It is generally acknowledged that IaaS and PaaS may lead to substantial savings, due to economies of scale, due to virtualization and due to the law of Moore (continued increase of price-performance ration in ICT infrastructural assets). Therefore, pure ASP offerings have been in competition with more general outsourcing value propositions form ICT service providers to customers. Accordingly, the ASP market has grown over the last decade, but Application Service Providing per sé it is not a disruptive technology.

\subsection{From Standard Software to Limited Configured Packaged Applications}

Standard ERP provides limited flexibility. The flexibility of these applications is determined by parameters. However, parameters increase complexity and costs. The same holds for customization tools. Moreover, customization tools shift the decoupling point back from MTS to ETO and returns to craftsmanship. Altogether, the dominant delivery model of ERP is MTS.

Moreover, the delivery model of standard software packages as ERP is not lean. The effort to implement these packages is dramatically high as compared to the mere software costs. After initial implementation, the dynamics of the customer cannot be easily captured to keep the system synchronized with the company progress. Last but not least, the dynamics of the vendor (new upgrades) cannot be properly managed.

These upgrading problems have motivated vendors of monolithic standard enterprise applications to strive for componentization of these monolithic applications. Many vendors announced that they split their ERP application to provide more flexibility for upgrading. Accordingly, vendors move towards an assemble-to-order mode of delivering configured enterprise applications. 
There are three other forces which drive vendors towards this componentization and the accompanying standardizations of interfaces between their components. These are new technologies, integration issues, and business process management.

\subsection{Servitization Using Single-Code Based Software Products}

Maintaining multiple different versions of a software component implies multiple investments in knowledge, multiple integration problems, multiple functionality issues and technology issues to be solved. This continues to hamper efficiency of service delivery. Multiple versions can never become lean delivery. To solve these issues, a variety of customers should be served from a single code base: a service provider has only one version of running code of an application suite, from which all customers are served software as-a-service (SaaS).

Together, IaaS, PaaS and SaaS constitute cloud computing. The advantage for the service supplieris, that the single code base dramatically reduces the effort in knowledge management and integration. Companies such as Force (see www.Force.com) claim to offer such a solution. However, this form of software delivery is not easy. For example, the data of all customers have to be kept separated, which is called multi-tennant database management.

\subsection{Servitization Using Single-Code Based Configurable Software Products}

The final step to a SaaS offering consists of configurable single-code based software components. In addition, a vast variety of vendors can offer other components for which there is a market, much like the apps stores in smart phones. Unlike these consumer apps, EIS components have considerable complexity due to at least the following three features:

- Components of EIS manage (structured) data

- Components of EIS collaborate via data integration or business process integration

- They use many devices, requiring adaptable user interfaces and interaction models.

An important question related to what is being configured. When thinking in analogies, then classical product configurators use parameters for configuration (see Section 2.2.).

If a configurator of enterprise information systems can work with a single code base for every component, it may lead to a very efficient delivery (lean) delivery model, which may cover a huge variety of requirements regarding functionality, deployment an ease of use. Such a development would complete the analogy of trends in physical goods and in enterprise information systems towards servitization, agility and variety. 


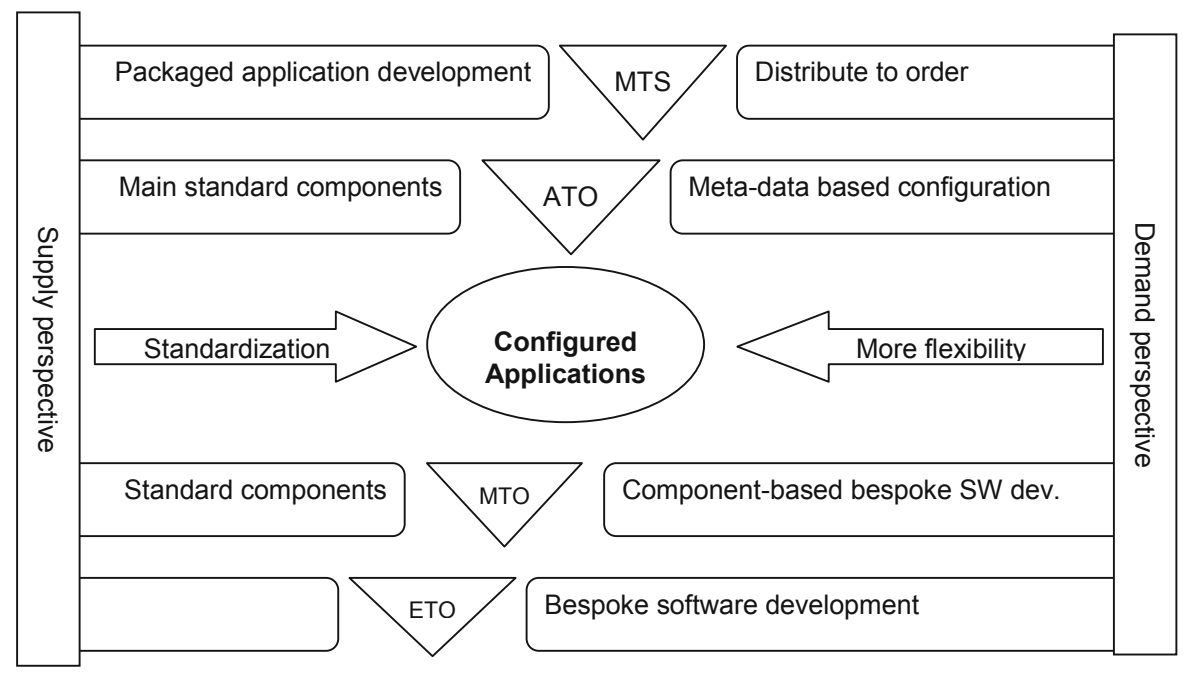

Fig. 3. Customer order decoupling point in enterprise information systems

\subsection{Re-engineering the Services Offered by Enterprise Apps}

In the realm of physical components, there is a tendency to increase the number of tiers in the bill-of-material. In the lower level components, vendors work for a world market, with a very few competitors. In automotive industry supply, there is only one supplier on earth for all gears inside the movable external mirror of a car. There are only a few suppliers of tires, mufflers, car radios, and so on. The economies of scale drive towards world dominance.

Exactly the same happens in the world of services. Services re-engineering creates a world of very elementary services which are shared across all kinds of applications (including enterprise applications). Some of the basis services which will be needed in a SaaS landscape are already visible.

The services available under a SaaS architecture (see figure 3) are all based on a set of ICT services such as storage (including backup and recovery), communication (including security), etc. On top of these ICT services, content related services will be offered.

One service which is needed often is an authentication ("Log-in") service: it constitutes a basic requirement for further user management SaaS applications to build on. A second service is related to open data such as related to the public space (postal addresses, traffic-related data and objects, measurements of noise, radiation, temperature, moist, substance etc.), events (health incidents, fires, calls for police services), statistics, utilities, etc. A third service which will anyway be needed is probably a (micro) payment infrastructure for other electronic services: after all, in business-to-business it is not tenable that all services are for free (as some consumers still believe). 
A fourth service which will be needed are services which allow granting authorization to third parties to use functionality or data. On top of such an authorization service, there will emerge the need for more sophisticated services to share documents and allow reuse of content in a way which is traceable, so that it can be licensed and that usage can be controlled. More sophisticated services related to geographic information is also likely to be needed.

\begin{tabular}{|c|c|}
\hline \multicolumn{2}{|c|}{ Vertical application services } \\
\hline $\begin{array}{c}\text { Sophisticated Content } \\
\text { Services }\end{array}$ & Geo content dervices \\
\hline Authorization & Basic (micro)payment services \\
\hline Authentication & Open data services (government) \\
\hline & Basic ICT services \\
\hline
\end{tabular}

Fig. 4. Basic set of services available under SaaS

\section{Conclusion}

In this paper, we explored the analogy between major trends in delivery of physical products as compared with the delivery of enterprise information systems. The similarities are striking.

Both in capital goods manufacturing and in enterprise information systems the earliest stage of maturity is characterized by craftsmanship. In capital goods, this is encountered as engineer-to-order manufacturing and delivery, whereas craftsmanship in enterprise information systems takes the form of bespoke software development.

The second stage of development is characterized by standard products. In enterprise information systems, it takes the form of standard packages of application software, such as ERP and CRM. Despite parameterization, these products remain standard products. Alternatively, when customization of these products is practised, the route back towards craftsmanship is paved.

Accordingly this paper conjectures that the next step in enterprise information systems is going to be an assemble-to-order delivery model based on configuration of standard main components. It will be a cloud service which has three distinct 
characteristics that differentiate it from traditional hosting. It is sold on demand, it is elastic -- a user can have as much or as little of a service as they want at any given time; and the service is fully managed by the provider (the consumer needs nothing but a personal computer and Internet access).

\section{References}

[1] Alblas, A.A., Zhang, L., Wortmann, J.C.: Representing Function-Technology Platform based on Unified Modelling Language. International Journal of Production Research (2011) (accepted for publication)

[2] Aurich, J.C., Wolf, N., Siener, M., Schweitzer, E.: Configuration of product-service systems. Journal of Manufacturing Technology Management 20(5), 591-605 (2009)

[3] Erens, F.J.: The synthesis of variety- developing product families. PhD dissertation, Eindhoven University of Technology (1996)

[4] Forza, C., Salvador, F.: Managing for variety in the order acquisition and fulfilment process: the contribution of product configuration systems. International Journal of Production Economics 76(1), 87-98 (2002)

[5] Hegge, H.M.H.: Intelligent product family descriptions for business applications. PhD dissertation, Eindhoven University of Technology (1992)

[6] Hoekstra, S., Romme, J.A.C.: Integral logistic structures. McGraw-Hill (1992) ISBN 0 77075528

[7] Meijler, T.-D., Pettersen Nytun, J., Prinz, A., Wortmann, J.C.: Supporting Fine-Grained Generative Model-Driven Evolution. Journal of Software and Systems Modelling (SOSYM) 9(3), 403-424 (2010)

[8] Mont, O.: Clarifying the concept of product-service system. Journal of Cleaner Production 10, 237-245 (2002)

[9] Olhager, J.: The role of the customer order decoupling point in production and supply chain management. Computers in Industry 61(9), 863-868 (2010)

[10] Shimomura, Y., Hara, T.: Method for supporting conflict resolution for efficient PSS Development. CIRP Annals - Manufacturing Technology 59(1), 191-194 (2010)

[11] Tukker, A., Tischner, U.: Product-Services as a Research Field: Past, Present and Future. Reflections from a Decade of Research. J. of Cleaner Prod. 14, 1552-1556 (2006)

[12] Womack, J.P., Jones, D.T., Roos, D., Sammons Carpenter, D.: The machine that changed the world: the story of lean production. HarperPerennial (1991) ISBN 006094179

[13] Wortmann, J.C., Alblas, A.A.: Product platform life cycles: a multiple case study. International Journal of Technology Management 48(2), 188-201 (2009) 